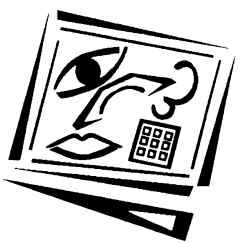

\title{
Laptop computers and wireless university campus networks: Is flexibility and effectiveness improved?
}

\author{
Miikka J. Eriksson, Hanna Vuojärvi and Heli Ruokamo \\ University of Lapland
}

\begin{abstract}
This study explores whether university students find that laptop computers and networks increase flexibility and effectiveness of studying. Special attention has been paid to non-traditional students who have extra commitments, such as taking care of children or term-time employment. Questionnaire data was collected from students who had the opportunity to acquire a laptop partly sponsored by the university. The data was analysed quantitatively. Results show that students with children particularly benefited from the support the laptops and networks provided. However, term-time employment did not influence students' experiences of flexibility or effectiveness in studying. Since it is increasingly common for university students to have other commitments along with their studies, this information can be utilised when planning teaching and student support practices.
\end{abstract}

\section{Introduction}

Employment and family responsibilities are commitments that limit the time spent on studying. In this article students with children or students who are working during term-time are referred to as non-traditional students, as opposed to traditional students who are studying full time without being committed to working and do not have children. Depending on the individual case, commitments might affect the number of available classes, impede participation in group work, restrict access to school facilities and limit interactions with faculty and fellow students. However, many students must work to finance their studies and living expenses, and having children should not be an obstacle to one's education either. According to a recent Eurostudent report (2005), 4 to $11 \%$ of university students have children and 20 to $91 \%$ are employed during term-time. In North America adult students over the age of 25, who often have these extra commitments, are actually one of the fastest growing groups of undergraduates (Carney-Crompton \& Tan, 2002). In the USA, almost $80 \%$ of undergraduate students identified themselves as being employed (Horn \& Malizio, 1998). Accordingly, Riggert, Boyle, Petrosko, Ash and Rude-Parkins (2006, p. 63) stated that "colleges and universities can no longer assume that the majority of students will be able to give their full time attention to academic endeavors".

The introduction of network based learning environments (NBLE) has increased the possibilities of distance learning, and therefore also the flexibility of higher education. Along with the development in NBLEs, numerous colleges and universities have initiated technology programs that introduce different mobile technologies (laptop computers, personal digital assistants, mobile phones) to further increase the flexibility of studying. A popular solution for higher education institutions has been the implementation of laptop programs that include personal laptop computers for 
students and, recently, also wireless local area networks (WLAN) that cover campus areas. Personal laptops are thought to increase the flexibility of studying by enabling computing anywhere and anytime, within the limitations set by batteries or availability of electricity. Laptops also provide storage space for students' personal files and study history. WLAN laptops increase also the availability of information and provide a wide range of communication tools that can be used to increase the effectiveness of studying. Despite the popularity of laptop programs among colleges and universities, articles exploring student experiences of laptop computers as studying tools are still scarce. This article aims to increase the knowledge of the ability of laptops and networks to increase the flexibility and effectiveness of studying and to find out whether student characteristics affect these experiences.

\section{Theoretical framework}

Students with commitments, like taking care of children or employment, often struggle with their schedules to integrate studies with their every day lives. Jacobs and Berkowitz-King (2002) argue that the tendency of older college students to enrol part time reflects the presence of competing social roles, and part time enrolment is the principal reason for lower completion rates at older ages. They also found that both full time and part time employment inhibited the chances of getting a degree. However, the literature provides inconsistent results concerning the effects of termtime employment on the progress of studies (reviewed in Riggert et al., 2006). Instead, having young children at home has been found to suppress the ability of women (Jacobs and Berkowitz-King, 2002) and divorced parents, regardless of gender, to complete their degree (Taniguchi \& Kaufman, 2005). Scott, Burns and Cooney (1996) also found that family responsibilities were the primary reason for female Australian university students with children for interrupting their studies. Therefore, it is probable that most students with commitments have a stronger need than other students for studying tools that increase flexibility and effectiveness. This is also supported by the results of Eriksson, Vuojärvi and Ruokamo (2008), as a study on university students' expectations showed that in particular students with commitments (taking care of children, employment during term-time) expected laptop computers and networks to facilitate the integration of learning with their everyday lives.

The definitions of flexible learning usually include the possibility of choosing study modes, the opportunity to access learning materials and instructors, and student responsibility for learning (Honey, 2004). It is obvious that laptops, together with networks, can increase the availability of learning materials and other information sources, but laptops also make a significant difference in study habits and in students' academic and social lives, and are also valuable studying tools in terms of helping students with classroom assignments, communication, and research (Demb, Erickson \& Hawkins-Wilding, 2004). In addition, Barak, Lipson and Lerman (2006) report positive perceptions of wireless laptops, as they enhance student centred, hands on, and exploratory learning. In the same research, students perceived laptops "as most useful and efficient for their learning". Newhouse, Williams and Pearson (2006) discuss that although the outcomes of their exploratory studies on the use of laptops in teacher education were generally positive, students still were reluctant to carry a relatively heavy device when they were unlikely to be asked to use it in lectures and tutorials. Some studies have also found laptops to be a distraction to both users and fellow students (Barak et al., 2006; Fried, 2008) and to interfere with students' abilities to pay attention to and understand the lecture material (Fried, 2008). However, despite 
some negative results, mainly related to laptop use during lectures, laptops and networks have the potential to improve students' time management efficiency by transforming former dead-time, e.g., in trains or while children are sleeping, into productive time. The flexibility that students experience as a result of their increased studying possibilities may also improve the results of their studying efforts, e.g. by speeding up graduation, and therefore also increasing the effectiveness of studying.

Based on the needs and expectations of non-traditional students and the mainly positive experiences of laptop use, it is hypothesised that these students consider personal laptops and networks as tools that increase the flexibility and effectiveness of studying more than traditional students. This hypothesis is also supported by the results of Donaldson (1999) who suggests that mature students, who usually have these commitments, are more able than younger ones to use different skills and strategies to compensate for their inability to partake all activities on campus. In addition, Hoskins and van Hooff (2005) propose that older students have a deeper approach to studying and a higher intrinsic motivation, which could prepare the way for a more effective use of available studying tools such as laptops and associated learning environments. Laptops thus afford the potential for self regulation and particularly the environmental aspect of it. Self regulation in education is understood as taking responsibility in learning through setting learning goals, and being aware of one's own actions and different factors that affect the process of achieving those goals. Environmental self regulation implies creating a suitable environment for studying and learning, for example by choosing a quiet place to study (Zimmerman, 1989). Mobile information and communication technologies can facilitate environmental regulation by affording flexibility regarding when and where to study. Being able to take charge of one's own learning and controlling the factors that have an influence on the learning process - such as management of time and place - may contribute significantly to study motivation (Zimmerman, 1998).

\section{Research questions}

Student opinions of the laptop initiative were surveyed at the University of Lapland with the objective of determining whether students consider laptop computers and networks as studying tools that increase the flexibility and effectiveness of studying. In addition, the question was studied whether commitments, such as taking care of children, term-time employment and being in a steady relationship, or characteristics like gender or age affect students' experiences with laptops. The study focused on university students who have access to a laptop and are actively using computers and networks. The specific research questions were:

1. Do students actively using computers and networks experience personal laptop computers and networks as study tools that increase flexibility and effectiveness?

2. Do commitments like having children, being employed during term-time and being in a steady relationship or characteristics like gender or age affect students' experiences with laptops and networks as studying tools that increase flexibility and effectiveness of studying?

\section{Context}

The University of Lapland is situated in the city of Rovaniemi, in northern Finland, and has about 4,500 students with about 550 to 700 new students enrolling each year. 
More than half of the students come from northern Finland. In the autumn of 2004 the university initiated a laptop program where new students where able to purchase a laptop computer partly sponsored by the university. Until spring 2008, four incoming classes have been able to purchase these laptops. Costs for students have been between 360 to $840 €$, depending on the year of purchase and the field of study - art students for example need faster computers for 3D-modelling and graphic design than other students. In 2004, 85\% of new students purchased the university laptop. However, as laptop computer prices have gone down more and more, many students already have their own laptop when entering university. Thus only 35\% of new students purchased a university laptop in 2007. All university laptops were equipped with a standard open source office software package, software for statistical analysis, and basic data security software such as a firewall and virus protection. In the Faculty of Art and Design, laptops for students were also equipped with some special software suitable for those students' needs.

Laptops also had a readiness for networking in wireless local area networks (WLANs). To support the use of laptops, a WLAN, covering all buildings at the campus area was launched, enabling students and faculty outside computer classes to access the Internet. For Internet access outside the campus area, for example at home, students needed some other Internet service provider. The inquiry showed that more than 95\% of respondents had the possibility to access the Internet also at home in spring 2008. University of Lapland provides all students enrolled a free email account and a remote access to university network also outside campus area. Student laptop use is supported through a helpdesk where students are able to get help in all computer related problems, like connecting the laptop to the university WLAN or problems with the university email. In addition, the university provides several computer rooms with desktop computers for student use.

The ways how laptop use is encouraged and facilitated vary greatly between disciplines and courses, and is very dependent on teachers' own initiatives. For example art students use laptops on a regular basis for 3D-modelling, graphic designing and audio-visual productions whereas social sciences students attend courses that include more lecture based teaching than hands on training and do not necessarily need laptops all the time. Teaching personnel have not been provided with training on how to take advantage of mobile technology in teaching. Some teachers are very interested in trying out different ways to conduct the courses they are responsible for, but some prefer doing things the way they are used to. All students have access to learning management system Oodi that enables registering to courses, giving feedback and following own records of completed studies. In addition, Optima Campus provides a network based learning environment where teachers can create working spaces to their courses, deliver material and receive course assignments from students.

\section{Methods}

\section{Data collection}

An online questionnaire was selected as an instrument for data collection. It is acknowledged that online questionnaires might be 'self selecting' by being unapproachable for participants who suffer from computer anxiety (Chua, Chen \& Wong, 1999 and references therein) or are otherwise infrequent users of computers. Therefore, it is supposed that students who are more likely to use the computers and 
networks are also more likely to complete an online survey. As the purpose of this study was to survey student experiences of the flexibility and effectiveness that laptops and networks provide, and to find out which student characteristics affect these experiences, it is important that respondents are actively using computers in their studies. In addition, only respondents who owned a university sponsored laptop or had access to some other laptop were allowed to answer the items related to experiences of laptop and network use.

The questionnaire was generated using the Webropol (http://www.webropol.com/). In April 2008, an email that included an introduction to the research, an invitation to participate in the survey, and a personal link to the questionnaire was sent to all 2,888 students who entered the University of Lapland in the fall of 2004 or later and who had agreed that their email address could be used for learning related polls. In addition, some students who had entered the University before the fall of 2004, but had later changed their major, were included. Reminder emails were sent a week later. The questionnaire was tested before delivery to students; overlapping questions were removed and the questionnaire was shortened. In the questionnaire, students were asked for background information (e.g. number of children, whether they worked during term-time, marital status, gender, age and faculty). The survey inquired into experiences and knowledge of using computers and the Internet, experiences of laptops and networks in teaching, studying and learning. Most of the questions were multiple choice, but some open ended questions were used also.

\section{Data analysis}

All data was analysed quantitatively using SPSS Version 15.0 (SPSS for Windows). Ten preselected items were exposed to factor analysis (principal component analysis; varimax rotation) to sort out the items that best describe flexibility and effectiveness of studying. Two factors with eigenvalues over 1.0 emerged (Table 1). To analyse the data further, individual questionnaire items, grouped by the factor analysis, were used to create two scales. The internal consistency of the created scales was tested by calculating Cronbach's alpha (Cronbach, 1951). Cronbach's alpha takes values from 0 (indicating no correlation) to 1 (indicating identical results) and an alpha value of about 0.7 or above is considered as evidence of acceptable internal consistency (Nunnally, 1978). The alpha value of 0.7 was exceeded in both scales, named "Flexibility" (alpha $=0.84)$ and "Effectiveness" (alpha $=0.85)$. Both scales were recoded into 5-point scales for contingency table analysis.

We applied the Kruskal-Wallis chi square test to analyse the association between the two scales and background information (contingencies). If possible, the exact significance was computed. Otherwise, a Monte Carlo estimation of the significance based on 10,000 samples was used (Mehta \& Patel, 1996). Because chi square test is sensitive to sample size, the strength of the relationship between variables was also calculated using Goodman and Kruskal's tau - an additional measure of association (Goodman \& Kruskal, 1954). The benefit of this index is that it measures the predictability of one categorical variable given the presence of another. Goodman and Kruskal's tau takes values between 0 (no association) and 1 (completely related). Statistical differences were deemed significant at $p=0.05$. In the results section only results deemed significant by both tests are mentioned as significant results. 
Table 1: Factor analysis (principal components; varimax rotation) results of ten preselected items describing student experiences of the ability of laptop computers and networks to enhance flexibility and effectiveness of learning

\begin{tabular}{|c|c|c|}
\hline \multirow{2}{*}{ Items } & \multicolumn{2}{|c|}{ Factors } \\
\hline & 1 & 2 \\
\hline $\begin{array}{l}\text { The use of laptop computer and networks has changed studying so that it is more } \\
\text { independent of time and place }\end{array}$ & .856 & \\
\hline $\begin{array}{l}\text { The use of laptop computers and networks has changed the routines of time } \\
\text { expenditure in studying }\end{array}$ & .811 & \\
\hline The use of laptop computer and networks has made studying more flexible & .846 & \\
\hline $\begin{array}{l}\text { The use of laptop computer and networks has made the integration of studying } \\
\text { and everyday life easier (e.g., concerning scheduling) }\end{array}$ & 625 & \\
\hline The use of laptop computer and networks has made studying more effective & & .607 \\
\hline The use of laptop computer and networks has speeded up your graduation & & .596 \\
\hline With the help of laptop computers and networks, you have studied more actively & & .711 \\
\hline $\begin{array}{l}\text { With the help of laptop computer and networks, you have achieved your learning } \\
\text { goals }\end{array}$ & & .689 \\
\hline $\begin{array}{l}\text { With the help of laptop computer and networks, your learning results have } \\
\text { improved }\end{array}$ & & .885 \\
\hline With the help of laptop computer and networks, you have learned quickly & & .811 \\
\hline
\end{tabular}

\section{Respondents}

The questionnaire was sent to 2,888 students and was returned by 392 respondents, representing $13.6 \%$ of the student population. Altogether, 575 students opened the link to the questionnaire, which means that 183 students either only checked the questionnaire or quit before reaching the last question. The proportion of male $(25.8 \%)$ and female $(74.2 \%)$ respondents, as well as the number of respondents from each faculty, represented the student population enrolled between 2004 and 2007 well. All four classes between 2004 and 2007 were also well represented, as their proportion varied between 0.20 and 0.26 . Respondents' mean age was 28.5 years (median $=25$ ), while the youngest students were 20 and the oldest was 59 years of age. Of the total 392 respondents, $22.2 \%$ had children, $48.5 \%$ were married or cohabiting, $19.1 \%$ were going steady and $32.4 \%$ were single. A majority of students worked during term-time, either regularly $(34.4 \%)$ or occasionally $(39.3 \%)$, while $26.3 \%$ of respondents did not work at all. A majority $(74.2 \%)$ of respondents had acquired a university sponsored laptop, $20.7 \%$ had a laptop from another source and $36.0 \%$ had a desktop. Almost all respondents $(96.7 \%)$ had access to the Internet at their apartment.

\section{Results}

The results show that although most respondents consider that personal laptops and networks increase the flexibility of studying, it does not automatically mean that the effectiveness of studying would also increase. Overall, $79.9 \%$ of respondents agreed or strongly agreed (later referred to as agreed) that laptops and networks increased flexibility of studying (mean $=4.06, \mathrm{SD}=0.82$; Table 2$)$, while only $38.8 \%$ agreed that this technology increased effectiveness of studying (mean $=3.28$, SD $=0.81$; Table 3). However, only $16.3 \%$ of respondents strongly disagreed or disagreed with the "effectiveness" scale while $47.7 \%$ responded "undecided". 
Table 2: Frequency (\%) of "Flexibility" and student background data including whether or not students have children, term-time employment, gender, age and marital status. Measures of association (Kruskal-Wallis chi square $=$ chi square, Goodman-Kruskal's tau $=$ tau) and their significance are also presented

\begin{tabular}{|c|c|c|c|c|c|c|}
\hline & $\begin{array}{c}1 \\
\text { Strongly } \\
\text { disagree }\end{array}$ & $\begin{array}{c}2 \\
\text { Disagree }\end{array}$ & $\begin{array}{c}3 \\
\text { Undecided }\end{array}$ & $\begin{array}{c}4 \\
\text { Agree }\end{array}$ & $\begin{array}{c}5 \\
\text { Strongly } \\
\text { agree }\end{array}$ & $\begin{array}{l}\text { Totals } \\
\text { (n) }\end{array}$ \\
\hline \multicolumn{3}{|l|}{ Have children } & \multicolumn{4}{|c|}{ chi square $=8.700, p=0.003^{\mathrm{a}} ; \mathrm{tau}=0.014, p=0.007^{\mathrm{a}}$} \\
\hline Yes & $2.7 \%$ & $1.3 \%$ & $9.3 \%$ & $41.3 \%$ & $45.3 \%$ & $100.0 \%(75)$ \\
\hline No & $0.7 \%$ & $3.1 \%$ & $18.1 \%$ & $51.4 \%$ & $26.7 \%$ & $100.0 \%(288)$ \\
\hline \multicolumn{3}{|c|}{ Term-time employment } & \multicolumn{4}{|c|}{ chi square $=0.794, p=0.421^{\mathrm{b}} ;$ tau $=0.002, p=0.911^{\mathrm{b}}$} \\
\hline Regularly & $0.8 \%$ & $3.3 \%$ & $18.3 \%$ & $46.7 \%$ & $30.8 \%$ & $100.0 \%(120)$ \\
\hline Occasionally & $0.7 \%$ & $2.0 \%$ & $14.3 \%$ & $52.4 \%$ & $30.6 \%$ & $100.0 \%(147)$ \\
\hline Not at all & $2.1 \%$ & $3.1 \%$ & $16.7 \%$ & $47.9 \%$ & $30.2 \%$ & $100.0 \%(96)$ \\
\hline \multicolumn{3}{|l|}{ Gender } & \multicolumn{4}{|c|}{ chi square $=12.691, p<0.001^{\mathrm{a}} ;$ tau $=0.010, p=0.025^{\mathrm{a}}$} \\
\hline Male & $3.3 \%$ & $4.3 \%$ & $23.9 \%$ & $48.9 \%$ & $19.6 \%$ & $100.0 \%(92)$ \\
\hline Female & $0.4 \%$ & $2.2 \%$ & $13.7 \%$ & $49.4 \%$ & $34.3 \%$ & $100.0 \%(271)$ \\
\hline \multicolumn{3}{|l|}{ Age } & \multicolumn{4}{|c|}{ chi square $=1.675, p=0.645^{\mathrm{b}} ;$ tau $=0.006, p=0.630^{\mathrm{b}}$} \\
\hline$<24$ & $0.0 \%$ & $2.7 \%$ & $19.5 \%$ & $52.2 \%$ & $25.7 \%$ & $100.0 \%(113)$ \\
\hline $24-25$ & $1.3 \%$ & $1.3 \%$ & $17.7 \%$ & $49.4 \%$ & $30.4 \%$ & $100.0 \%(79)$ \\
\hline $26-29$ & $1.2 \%$ & $3.6 \%$ & $12.0 \%$ & $51.8 \%$ & $31.3 \%$ & $100 \%(83)$ \\
\hline$>29$ & $2.3 \%$ & $3.4 \%$ & $14.8 \%$ & $43.2 \%$ & $36.4 \%$ & $100.0 \%(88)$ \\
\hline \multicolumn{3}{|l|}{ Marital status } & \multicolumn{4}{|c|}{ chi square $=1.294, p=0.528^{\mathrm{b}} ;$ tau $=0.003, p=0.699^{\mathrm{b}}$} \\
\hline $\begin{array}{l}\text { Married or } \\
\text { cohabiting }\end{array}$ & $1.2 \%$ & $2.3 \%$ & $14.6 \%$ & $49.1 \%$ & $32.7 \%$ & $100.0 \%(171)$ \\
\hline Going steady & $1.4 \%$ & $0.0 \%$ & $16.4 \%$ & $54.8 \%$ & $27.4 \%$ & $100 \%(73)$ \\
\hline Single & $0.8 \%$ & $5.0 \%$ & $18.5 \%$ & $46.2 \%$ & $29.4 \%$ & $100 \%(119)$ \\
\hline Totals & $1.1 \%$ & $2.8 \%$ & $16.3 \%$ & $49.3 \%$ & $30.6 \%$ & $100.0 \%(363)$ \\
\hline
\end{tabular}

${ }^{\text {a }}$ Exact significance; ${ }^{b}$ Monte Carlo Significance based on 10,000 samples

Cross-tabular analyses (Kruskal-Wallis chi square and Goodman and Kruskal's tau) were performed to find out the significant associations between experiences of both flexibility and effectiveness and student commitments like having children, being employed during term-time, and being in a steady relationship and characteristics like gender and age. Results show that of the tested commitments, only having children was significantly associated with both flexibility and effectiveness of studying. A significantly greater number of students with than without children reported that laptops and networks had increased both the flexibility (86.6 and 78.3\%, respectively; Table 2) and the effectiveness (54.0 and $35.0 \%$, respectively; Table 3 ) of studying. However, experiences of flexibility or effectiveness were not associated with employment. The only association found concerning marital status was the association with effectiveness of studying, based on chi square test, but Goodman and Kruskal's tau did not support this conclusion. If students with children were excluded from the analysis, even the chi square test indicated that marital status was not a significant factor.

In addition to commitments, also the association of gender, age, marital status and faculty with flexibility and effectiveness of studying was tested. Association between gender and flexibility was significant, as a greater number of women $(83.7 \%)$ than men 
$(68.5 \%)$ agreed that laptops and networks have increased the flexibility of studying (Table 2). If students with children were excluded from analysis, the difference between genders still remained significant based on chi square analysis (chi square = 9.685, $p=0.002$ ), but not quite with Goodman and Kruskal's tau (tau =0.009, $p=0.065$ ). Gender, however, did not affect experiences of technology's ability to enhance the effectiveness of studying. Students' age was significantly associated with experiences of effectiveness (Table 3), as 55.2\% of the oldest students (>29 years) and 29.1 to $37.7 \%$ of younger students ( $\leq 29$ years) agreed with the effectiveness scale. Experiences of flexibility, however, were not associated with students' age (Table 2). Faculty did not effect experiences of flexibility, but Goodman and Kruskal's tau indicated an association between faculty and effectiveness of learning (chi square $=4.729, p=0.307$; tau $=0.032, p=0.004$ ). Students from the Faculty of Education, the Faculty of Business and Tourism, and the Faculty of Social Sciences seemed to have more positive experiences of laptops' and networks' ability to increase effectiveness of studying as $45.4,46.1$ and $41.5 \%$, respectively, of students agreed with the 'effectiveness' scale, while only 31.8 and $25.5 \%$ of students from the Faculty of Law and the Faculty of Art and Design, respectively, agreed with this scale.

Table 3: Frequency (\%) of "Effectiveness" and student background data including whether or not students have children, term-time employment, gender, age and marital status. Measures of association (Kruskal-Wallis Chi square = chi square,

Goodman-Kruskal's tau $=$ tau) and their significance are also presented

\begin{tabular}{|c|c|c|c|c|c|c|}
\hline & $\begin{array}{c}1 \\
\text { Strongly } \\
\text { disagree }\end{array}$ & $\begin{array}{c}2 \\
\text { Disagree }\end{array}$ & $\begin{array}{c}3 \\
\text { Undecided }\end{array}$ & $\begin{array}{c}4 \\
\text { Agree }\end{array}$ & $\begin{array}{c}5 \\
\text { Strongly } \\
\text { agree }\end{array}$ & $\begin{array}{l}\text { Totals } \\
\text { (n) }\end{array}$ \\
\hline \multicolumn{3}{|l|}{ Have children } & \multicolumn{4}{|c|}{ chi square $=9.501, p=0.002^{\mathrm{a}} ;$ tau $=0.011, p=0.017^{\mathrm{a}}$} \\
\hline Yes & $2.7 \%$ & $5.4 \%$ & $37.8 \%$ & $45.9 \%$ & $8.1 \%$ & $100.0 \%(74)$ \\
\hline No & $2.1 \%$ & $12.8 \%$ & $50.2 \%$ & $31.5 \%$ & $3.5 \%$ & $100.0 \%(289)$ \\
\hline \multicolumn{3}{|c|}{ Term-time employment } & \multicolumn{4}{|c|}{ chi square $=0.993, p=0.606^{\mathrm{b}} ;$ tau $=0.005, p=0.456^{\mathrm{b}}$} \\
\hline Regularly & $3.4 \%$ & $9.2 \%$ & $47.1 \%$ & $35.3 \%$ & $5.0 \%$ & $100.0 \%(119)$ \\
\hline Occasionally & $1.3 \%$ & $8.7 \%$ & $51.7 \%$ & $34.2 \%$ & $4.0 \%$ & $100.0 \%(149)$ \\
\hline Not at all & $2.1 \%$ & $17.9 \%$ & $42.1 \%$ & $33.7 \%$ & $4.2 \%$ & $100.0 \%(95)$ \\
\hline \multicolumn{3}{|l|}{ Gender } & \multicolumn{4}{|c|}{ chi square $=0.259, p=0.611 ;$ tau $=0.002, p=0.413$} \\
\hline Male & $3.3 \%$ & $15.2 \%$ & $42.4 \%$ & $33.7 \%$ & $5.4 \%$ & $100 \%(92)$ \\
\hline Female & $1.8 \%$ & $10.0 \%$ & $49.4 \%$ & $34.7 \%$ & $4.1 \%$ & $100 \%(271)$ \\
\hline \multicolumn{3}{|l|}{ Age } & \multicolumn{4}{|c|}{ chi square $=8.795, p=0.033^{\mathrm{b}} ;$ tau $=0.030, p=0.002^{\mathrm{b}}$} \\
\hline$<24$ & $0.9 \%$ & $14.3 \%$ & $50.9 \%$ & $30.4 \%$ & $3.6 \%$ & $100.0 \%(112)$ \\
\hline $24-25$ & $2.5 \%$ & $7.6 \%$ & $60.8 \%$ & $22.8 \%$ & $6.3 \%$ & $100.0 \%(79)$ \\
\hline $26-29$ & $2.4 \%$ & $12.9 \%$ & $47.1 \%$ & $36.5 \%$ & $1.2 \%$ & $100.0 \%(85)$ \\
\hline$>29$ & $3.4 \%$ & $9.2 \%$ & $32.2 \%$ & $48.3 \%$ & $6.9 \%$ & $100.0 \%(87)$ \\
\hline \multicolumn{3}{|l|}{ Marital status } & \multicolumn{4}{|c|}{ chi square $=10,023, p=0.007^{\mathrm{b}} ; \mathrm{tau}=0.010, p=0.102^{\mathrm{t}}$} \\
\hline $\begin{array}{l}\text { Married or } \\
\text { cohabiting }\end{array}$ & $1.8 \%$ & $8.8 \%$ & $42.7 \%$ & $39.8 \%$ & $7.0 \%$ & $100 \%(171)$ \\
\hline Going steady & $2.8 \%$ & $12.5 \%$ & $55.6 \%$ & $26.4 \%$ & $2.8 \%$ & $100 \%(72)$ \\
\hline Single & $2.5 \%$ & $14.2 \%$ & $50.0 \%$ & $31.7 \%$ & $1.7 \%$ & $100 \%(120)$ \\
\hline Totals & $2.2 \%$ & $11.3 \%$ & $47.7 \%$ & $34.4 \%$ & $4.4 \%$ & $100 \%(363)$ \\
\hline
\end{tabular}

${ }^{\mathrm{a}}$ Exact significance; ${ }^{\mathrm{b}}$ Monte Carlo Significance based on 10,000 samples 


\section{Discussion}

This study indicates that particularly those students with children considered personal laptops and networks as studying tools that increase the flexibility and effectiveness of their studying. Although it was hypothesised that all non-traditional students (students with children and students working part or full time during term-time) would consider that these tools increase flexibility and effectiveness of studying more than traditional students, employment during term-time did not influence these experiences. A prior survey inquiring into students' expectations showed that both commitments, whether or not students have children and whether or not they work during term-time, affected students' expectations of the way in which laptops and networks could support the integration of studying in their everyday lives (Eriksson, Vuojärvi \& Ruokamo, 2008). This suggests that both groups need flexible studying and that they think technology supported learning can at least partly solve their scheduling problems. The large proportion $(22.2 \%)$ of students with children among respondents, compared to the $10 \%$ of students with children among all university students in Finland (Viuhko, 2006), shows that students with children were over-represented among respondents. This suggests that they set great store by the theme of this questionnaire.

The difference in experiences between students with children and employed students might stem from the differing nature of these two commitments. Employment ties the worker to his/her place of work only for a certain period of time, leaving for example evenings or weekends free for studying. When most of the studying activities take place at home, a laptop does not provide much additional flexibility compared to a desktop - maybe just the possibility of choosing one's place of study between desk and couch. Taking care of children, however, is more of a twenty-four/seven job where the opportunities for studying cannot always be predicted. It is possible that because of their 'unpredictable learning environments' students with children have a greater need for flexible studying tools than working students. They have, therefore, benefited more from laptops and networks that allow learning where and when it best suits the student, which consequently improves the possibilities for efficient time management - one of the self-regulatory processes suggested by Zimmerman (1998).

Laptops also allow students to self regulate their studying environments (cf. Zimmerman, 1998), for example, by seeking a quiet place for studying while the other parent is taking care of children or by enabling studying in the backyard while children are taking their afternoon nap or playing under their parents' surveillance. The possibilities of taking charge of one's own studying may contribute significantly to study motivation, which is necessary for students' proactive efforts, personal initiative, resourcefulness, persistence, and sense of responsibility, to learn on their own (Zimmerman, 1998). As self regulation is not considered a fixed characteristic of students but rather a context specific process that is selectively used to succeed in school (Zimmerman, 1998), it is possible that students with children are more eager to take advantage of the self regulatory capacity that laptops and networks offer. This could consequently lead to experiences of more effective learning. The difference between these two commitments is also evident from previous studies that show that having children has mostly negative effects on the progress of studies (e.g., Jacobs \& Berkowitz-King, 2002; Taniguchi \& Kaufman, 2005), while the results of studies that evaluate student employment and higher education are at times inconsistent or even contradictory (reviewed in Riggert et al., 2006). 
In the present research, gender was found to affect experiences of flexibility significantly, as $83.7 \%$ of women and $68.5 \%$ of men considered that laptops and networks enhance the flexibility of learning. Differences between genders in experiences of the effectiveness of studying were, however, not found. The result concerning the flexibility of learning is quite the opposite to many studies published during the last decades, which report a digital divide between genders from elementary school to higher education, with females expressing greater computer anxiety and more negative attitudes than males (reviewed by Cooper, 2006). Partly, the result is explained by the selective data collection method, that could have excluded students who either suffer from computer anxiety or are otherwise infrequent users of computers and the Internet. However, some recent studies have also shown that the gender gap is decreasing, at least in attitudes towards computers (Link \& Marz, 2006; Teo, 2008) and online abilities (Hargittai \& Shafer, 2006). However, despite women's actual abilities, women still self assessed their skill level significantly lower than men (Hargittai \& Shafer, 2006).

Although age did not significantly affect experiences of flexibility, it did however have a significant effect on experiences of effectiveness, with older students $(>29)$ in particular experiencing laptops and networks as enhancing effectiveness of their studies. One explanation for the result could be older students' deeper approach to studying and higher intrinsic motivation (Hoskins \& Hooff, 2005) that prepare the way for a more effective use of available tools such as laptops and associated learning environments. In an earlier study Barak et al. (2006; p. 257) reported that senior students valued active learning through the use of laptop computers more than other students, and suggested that "the more mature and ready for scholarly pursuits the students are, the better they understand the importance and effectiveness of being active in their learning". Actually, a closer look at the responses to the individual item 'With the help of laptop computers and networks, you have studied more actively' show that a significantly larger part of older $(48.3 \%)$ than younger students (30.4$36.0 \%$ ) agreed or strongly agreed with the statement.

Although most definitions of flexible studying include the possibility of choosing study modes, the opportunity to access learning materials and staff, and student responsibility for learning (Honey, 2004), our 'flexibility' scale has more to do with the possibility of using laptops for studying when and where it best suits the student. This independence of time and place consequently leads to changes in the routines of time expenditure, and also makes the integration of studies with everyday life easier. 'Effectiveness' scale, instead, mainly describes how laptops and networks have affected the progress of studies. Overall, almost $80 \%$ of respondents thought that laptops and networks increased flexibility, while less than $40 \%$ thought that the effectiveness of learning increased with the use of these tools. When interpreting these results, one must remember that the respondents do not represent all students of the University of Lapland, but focuses on those actively using computers and networks. Keeping the study method in mind, the results suggest that experiences of flexibility do not automatically lead to more effective studying and that a large part of the supportive value of laptops and networks for students consists of the opportunity to do their assignments at home, on campus or wherever the opportunity arises. The result that only $39 \%$ of respondents thought that laptops and networks increase effectiveness of studying could be an indication of a failure to integrate laptops into faculties' curricula. 
According to Demb et al. (2004), students' perceptions of the value of their laptops in relation to their academic success have been found to correlate tightly with their perceptions of how successful the faculty has been in terms of integrating laptops into teaching and classroom activities. This is probably also the case in the University of Lapland as there were significant differences between faculties in students' experiences concerning the effectiveness of studying. In practice, this could mean that there are currently, at least in some faculties, insufficient possibilities for distance learning and/or too much of a focus on mandatory attendance at lectures. Experiences at Winona State University show that "access to laptops is not sufficient to support and transform pedagogy. Successful implementation depends on support from administration, technology staff, and individual departments" (McVay et al., 2005; p. 514). It therefore seems that the faculties and technology staff at the University of Lapland still have much work to do to integrate laptops and wireless networks successfully into the curriculum and teaching practices.

Results indicate clearly that laptops and networks can increase flexibility of studying for both traditional and non-traditional students but also that a considerably lower proportion of students experienced an improvement in effectiveness of studying. The key for improving also the effectiveness of studying is careful planning of teaching and student support practices. It seems to be beneficial for students if they have more choice on how they want to study the courses they are enrolling in (e.g. Honey, 2004), for example a possibility to choose whether they want to take an exam or write an essay. This would increase both flexibility and students responsibility for their own learning and probably also their motivation, which has been found to be positively related with several aspects of successful self regulated learning (Zimmerman, 1998). Mandatory attendance at lectures can rule out enrolling in some course entirely if, for example, a student has to take care of children at the same times. It could be contemplated if lectures could be recorded and saved in network based learning environments, in which students could watch them at a more convenient time. With the help of video conferencing hardware and software, lectures can also be broadcast in real time if recording is out of question, for example due to material rights issues that are now topical in education because of fast growth of the amount of digital material provided for students.

Effectiveness of studying can also be promoted by careful planning of students' own personal studying paths. Currently, students in the University of Lapland have both student and teacher tutors who help them in planning their studies. It is however presumable that these tutors have a deep knowledge only of their own discipline, which is problematic because it is common for students to take courses in other faculties also. Perhaps student guidance could be carried out in multi-disciplinary teams that have knowledge on the completion possibilities in different faculties. This would help students to plan their academic year in more detail, taking into account how they may benefit from mobile technology in different courses they are planning to take. It needs to be borne in mind that commitments such as having children are the starting point that dictates how other activities take place in students' lives. Detailed plans and schedules provide predictability that helps students' planning of their everyday lives in general, and not just their studies. 


\section{Conclusion}

It is increasingly common for university students to have other commitments alongside their studies. Therefore, it is of the utmost importance that this is acknowledged by universities as they plan their teaching practices and student support structures in particular. Failing to do so may result in lengthening studying spans or increasing the drop out rate - these are consequences that today's efficiency focused university strategies aim to avoid. As almost $80 \%$ of all respondents and over $85 \%$ of students with children agreed that laptops and networks increase the flexibility of studying, and more than half of the students with children and older students also experienced that laptops and networks increased the effectiveness of studying, the practical implication of this research is that the use of laptops should be encouraged and that the laptop program should continue.

However, the low overall percentage of respondents (39\%) agreeing with the effectiveness scale suggest that most of the students are not taking full advantage of the possibilities these learning tools offer. It is probable that some of these students simply do not need more effective studying tools, but it is also possible that a significant proportion of students do not have such self regulation skills that enable these supportive mobile technologies efficiently. Training for self regulative skills like goal setting, self monitoring, time management or environmental structuring (e.g. Zimmerman, 1998) should be part of each student's education. In addition, teachers should be given opportunities to develop their skills as instructors who can promote the use of laptop and WLAN technologies. Development of one's own work requires time to deliberate upon different possibilities and to think what, for example, would be the best way to support collaborative discourses, deliver material or give feedback for students. If there is not enough time for course development in a teachers' work plan, it is easier to continue the same way as earlier than make hasty alterations in course design.

Because of the low response rate, which is typical for email surveys (eg, Kaplowitz, Hadlock \& Levine, 2004), and the possible bias in respondents towards those actively using computers and networks, these results should not be generalised to represent all students at the university. The possible bias amongst responding students should not, however, be taken as a weakness in the data, as students actively using computers and networks are exactly the group that can best estimate the possible benefits these studying tools can offer. This paper adds to the still limited literature concerning laptop computers and networks as tools that afford flexibility and effectiveness for non-traditional students. Our results demonstrate the need for further research to determine the special concerns and needs of non-traditional students, and how those needs can be addressed.

\section{Acknowledgments}

The results reported here are part of a larger MobIT project (Developing Mobile Network Based Teaching, Studying and Learning Processes, http:// www.ulapland.fi/?deptid= 18876) surveying university students' expectations and experiences of laptop computers and networks. A full list of publications related to this project is given at the URL http: / / www.ulapland.fi / ?deptid=23322. The project is funded by the Ministry of Education for the years 2007-09. 


\section{References}

Barak, M., Lipson, A. \& Lerman, S. (2006). Wireless laptops as means for promoting active learning in large lecture halls. Journal of Research on Technology and Education, 38(3), 245-263.

Carney-Crompton, S. \& Tan, J. (2002). Support systems, psychological functioning, and academic performance of nontraditional female students. Adult Education Quarterly, 52(2), 140-154.

Chua, S. L., Chen, D.-T. \& Wong, A. F. L. (1999). Computer anxiety and its correlates: A metaanalysis. Computers in Human Behavior, 15(5), 609-623.

Cooper, J. (2006). The digital divide: The special case of gender. Journal of Computer Assisted Learning, 22(5), 320-334.

Cronbach, L. J. (1951). Coefficient alpha and the internal structure of tests. Psychometrika, 16(3), 297-334.

Demb, A., Erickson, D. \& Hawkins-Wilding, S. (2004). The laptop alternative: Student reactions and strategic implications. Computers $\mathcal{E}$ Education, 43(4), 383-401.

Donaldson, J. F. (1999). A model of college outcomes for adults. Adult Education Quarterly, 50(1), $24-40$.

Eriksson, M. J., Vuojärvi, H. \& Ruokamo, H. (2008). University students' expectations of laptop computers and networks as learning tools that support everyday life. Manuscript submitted for publication.

Eurostudent (2005). Social and economic conditions of student life in Europe 2005: Synopsis and national profiles for Austria, Belgium (Flemish county), Belgium (Wallonia-Brussels Community), Finland, France, Ireland, Italy and The Netherlands. Hannover: HIHS Hochschul-InformationsSystem. http://www.his.de/Eurostudent/download/eurostudent2000.pdf [viewed 15 Aug 2008]

Fried, C. B. (2008). In-class laptop use and its effects on student learning. Computers $\mathcal{E}$ Education, 50(3), 906-914.

Goodman, L. A. \& Kruskal, W. H. (1954). Measures of association for cross classifications. Journal of the American Statistical Association, 49, 732-764.

Hargittai, E. \& Shafer, S. (2006). Differences in actual and perceived online skills: The role of gender. Social Science Quarterly, 87(2), 432-448.

Horn, L. J. \& Malizio, A. (1998). Undergraduates who work: National postsecondary student aid study, 1996 (National Center for Education Statistics, U.S. Department of Education, Office of Educational Research and Improvement Publication No. NCES 98-137). Washington DC: Government Printing Office.

Honey, M. (2004). Flexible learning for postgraduate nurses: A basis for planning. Nurse Education Today, 24(4), 319-325.

Hoskins, S. L. \& van Hooff, J. C. (2005). Motivation and ability: Which students use online learning and what influence does it have on their achievement? British Journal of Educational Technology, 36(2), 177-192.

Jacobs, J. A. \& Berkowitz King, R. (2002). Age and college completion: A life-history analysis of women aged 15-44. Sociology of Education, 75(3), 211-230. 
Kaplowitz, M. D., Hadlock, T. D. \& Levine, R. (2004). A comparison of Web and mail survey response rates. Public Opinion Quarterly, 68(1), 94-101.

Link, T. M. \& Marz, R. (2006). Computer literacy and attitudes towards e-learning among first year medical students. BMC Medical Education, 6:34 doi:10.1186/1472-6920-6-34. http: / / www.biomedcentral.com/ content/pdf/1472-6920-6-34.pdf [viewed 12 Sep 2008]

McVay, G. J., Snyder, K. D. \& Graetz, K. A. (2005). Evolution of a laptop university: A case study. British Journal of Educational Technology, 36(3), 513-524.

Mehta, C. R. \& Patel, N. T. (1996). SPSS Exact Tests 7.0 for Windows. SPSS Inc.

Newhouse, C. P., Williams, P. J. \& Pearson, J. (2006). Supporting mobile education for preservice teachers. Australasian Journal of Educational Technology, 22(3), 289-311. http:/ / www.ascilite.org.au/ajet/ajet22/newhouse.html

Nunnally, J. C., (1978). Psychometric theory. (2nd ed.), McGraw-Hill, New York.

Riggert, S. C., Boyle, M., Petrosko, J. M., Ash, D. \& Rude-Parkins, C. (2006). Student employment and higher education: Empiricism and contradiction. Review of Educational Research, 76(1), 6392.

Scott, C., Burns, A. \& Cooney, G. (1996). Reasons for discontinuing study: The case of mature age students with children. Higher Education, 31(2), 133-253.

Taniguchi, H. \& Kaufman, G. (2005). Degree completion among nontraditional college students. Social Science Quarterly, 86(4), 912-927.

Teo, T. (2008). Assessing the computer attitudes of students: An Asian perspective. Computers in Human Behavior, 24(4), 1634-1642.

Viuhko, M. (2006). Opiskelijatutkimus 2006 (Student Survey 2006 - Studies, Income and Paid Work) (In Finnish with English summary). Helsinki, Finland: Ministry of Education.

Zimmerman, B. J. (1998). Academic studying and the development of personal skill: A selfregulatory perspective. Educational Psychologist, 33(2/3), 73-86.

Zimmerman, B. J. (1989). A social cognitive view of self-regulated academic learning. Journal of Educational Psychology, 81(3), 329-339.

Miikka J. Eriksson, Hanna Vuojärvi and Heli Ruokamo

Centre for Media Pedagogy, University of Lapland

PO Box 122, FI - 96101 Rovaniemi, Finland

Web: http: / / www.ulapland.fi / ?Deptid=18876

Corresponding author: Miikka.Eriksson@ulapland.fi 